\title{
Diversity and Abundance of Insectivorous Passerines and Insect Prey in an Urban Degraded Savanna Woodland
}

\author{
*1TURSHAK, LG; ${ }^{2}$ MWANSAT, GS \\ ${ }^{* 1}$ Biological Sciences Techniques, Department of Science Laboratory Technology, University of Jos, Nigeria. \\ ${ }^{2}$ Department of Zoology, University of Jos, Jos, Plateau State, Nigeria \\ *Corresponding Author Email: lturshak@unijosedu.ng; longtee2008@gmail.com
}

\begin{abstract}
A good supply of insects in the diet of birds is vital for survival. Insects provide a high and easily assimilated source of protein essential to avian species life process. Both insects and birds are useful bio-indicators of the environment and therefore important systems for biodiversity conservation. This study was carried out at the Jos Wildlife Park located within the Jos Plateau. The Park is characterized by savanna scrub, gallery forests with seasonal streams, gentle hills and rocky outcrops and some exotic plants. Insectivorous passerines were trapped using mist nets to obtain faecal droppings which were then preserved in $70 \%$ alcohol and taken to the laboratory for microscopic examination of insect fragments. Line transect was used to survey insectivorous passerines and insects in different habitat types. Insect surveys involved the use of sweep netting and pitfall trapping techniques along transects. A total of 151 bird species in 48 Families were recorded whereas a total of 91 insect species were identified in 17 Orders and 87 Families during this study. In addition, insects collected along the transect line pointed out that the Order Hymenoptera> Diptera> Coleoptera> Orthoptera. The positive correlation between insects sampled from the faecal dropping of insectivorous passerines and those collected from the habitat types in the study area perhaps suggest that the insect diet of the insectivorous passerines is a reflection of the frequency of insect abundance and diversity in the study area. The study concludes that insectivorous passerines had a direct correlation between habitat resource availability and utilization
\end{abstract}

\section{DOI: https://dx.doi.org/10.4314/jasem.v25i6.3}

Copyright: Copyright $(92021$ Turshak and Mwansat. This is an open access article distributed under the Creative Commons Attribution License (CCL), which permits unrestricted use, distribution, and reproduction in any medium, provided the original work is properly cited.

Dates: Received: 20 March 2021; Revised: 27 April 2021; Accepted: 07 May 2021

Keywords: Insects, Passerines, Birds, Habitat, Abundance and Diversity.

Considerable attention has been directed toward bird population, sparked by concern over reported declines of species on a global scale (Robbins et al. 1989; Balmford et al. 2001; MacKenzie and Nichols, 2004). Much of this attention is focussed on bird habitatrelationships, more so with the increasing evidence (Balmford et al. 2001) that areas of outstanding conservation importance may coincide with areas of dense human population settlement or impact. Studies have shown that, for terrestrial communities, the number and diversity of bird species are strongly positively correlated with some vegetation variables (MacArthur 1964; Recher 1985; Karr and Roth 1971). Studies of avian habitat use have strongly influenced both habitat management programmes and ecological theory. Avian habitat selection is essentially related to attributes of habitats that are selected for measurement in field studies and therefore a wise selection of variables is important (Rice et al. 1984). This study therefore determined whether insectivorous passerine diversity and abundance correlate those of their insect prey across different habitat types of the Jos Wildlife Park, a semi-degraded savanna woodland.

\section{MATERIALS AND METHODS}

Study Area: This study was carried out at the Jos Wildlife Park located within the Jos Plateau, Nigeria. The Park is located to the south west of Jos, Plateau State, Nigeria, at Latitude $09^{\circ} 52^{\prime}$ and Longitude $08^{\circ}$ $53^{\prime}$ and covers an area of $12 \mathrm{~km}^{2}$. It is characterized by savanna woodlands, gallery forests with seasonal streams, gentle hills and rocky outcrops and some exotic plants. The Park is a protected area that prohibits unauthorized activities such as farming, grazing, bush burning, and collection of wood and timber products, hunting, refuse dump and indiscriminate entry by humans. There are also captive animals and a safari area.

The vegetation is dominated by the presence of Jacaranda mimosaefolia, Parkia clappertonia, Ficus species, Dedonix rejia and Acacia species. Introduced trees such as Pinus and Eucalyptus species are common. Herbs and shrubs like Sida acuta, Bohemia species and Emilia sonchiofolia are also present. The forest has been identified as one of the relatively undisturbed natural vegetation of the Jos Plateau (Mannok, 2006). These characteristics of the Jos 
Wildlife Park predisposed its choice as a suitable site for this study.

Bird census, trapping and handling: Line transects (Bibby et al., 2000) were used to evaluate bird species composition of the study area. Nine transects of $1000 \mathrm{~m}$ length ( 3 in each habitat type) were placed in the reserve randomly. Each transect was surveyed once in a month for a period twelve months from March 2009 to February 2010. During each visit, transects were walked slowly, while listening, looking for and recording birds. A Global Positioning (Satellite) System (GPS; Garmin eTrex®, version 3.10) was used to locate transect and plots for vegetation measurements. Bird surveys were carried out in the mornings, between 0630 hours and 1100 hours and in the afternoons between 16:00 hours to 18:00 hours. Three $9 \mathrm{~m}$ and two $12 \mathrm{~m}$ long mist nets were randomly placed in the reserve to trap insectivorous passerines. Mounted mist nets were intermittently checked for possible catch after every 20 minutes. Mist netting was carried out every other month for a period of five days between the months of April 2009 and March 2010.

Collection and identification of faecal samples: Captured individual birds were extracted from the mistnet and identified and kept in a wooden box measuring for 15 minutes; this created a dark interior suitable for the discharge of faeces. Birds that did not pass out faecal droppings within the stipulated time were released. Red nail varnish was used to mark trapped birds on the left claw of the hind toe in order to distinguish between trapped and untrapped birds. First and second retrap were marked with red and black nail vanish respectively. Faecal samples collected from an individual bird were preserved in $70 \%$ alcohol (ethanol) and kept in labeled sample tubes for examination in the laboratory. Each faecal sample was decanted into a Petri-dish to aid identification of insect fragments passed through the gut of the bird because of their indigestibility. Large insect parts were viewed with hand lens, while smaller insect fragments were viewed with the aid of a binocular microscope. Every section of the Petri-dish was searched carefully, and specimens were identified to the taxonomic level of Order. Number of large insect fragments per sample was also recorded. Identification keys described by Borror and White, (1970); Skaife, (1979); Castner, (2000) and Shattuck, (2000).

Insect survey design: Insects were sampled between January 2009 and February 2011. The same transects used to census birds in the different habitat types were also used to sample insects. This involved the use of sweep netting and pitfall trapping techniques as described by Kent and Coker, (1992) and Sutherland,
(1996). The identification keys of Borror and White (1970); Skaife (1979); Castner (2000) and Shattuck (2000) were used for insect identification.

\section{RESULTS AND DISCUSSION}

A comparison between insect Orders identified from the faecal droppings of trapped insectivorous passerines and insects sampled from the field using sweep-net and pitfall traps showed that the Orders Hymenoptera, Diptera, Coleoptera, Orthopthera, Lepidoptera, Odonata, Isoptera, Hemiptera, Mantodae, Homoptera and Trichoptera were all represented in both insects sampled from faecal droppings and those from the field, while Neuroptera, Mecoptera, Thysanoptera, Dermaptera, Phasmatodae and Blatteria were only represented from the field collection (Figure 1). Undigested insect fragments or insect prey remains from the faecal samples of insectivorous passerines included complete heads, mouth parts, thoracic segments, abdominal segments, wings, raptorial, head capsule, legs, elytra, targal plate, antenna, arista, eye, proboscis, scales and spine. The microscopic examination of these insect parts generated frequencies in this order: leg> elytra> wing $>$ mandible $>$ head $>$ abdomen $>$ thorax $>$ raptorial as shown in Figure 2.

In terms of habitat use, there was a significant difference in insectivorous passerines abundance in the savanna, gallery forest and rocky outcrop (KrukalWallis test: $\mathrm{df}=2, \chi^{2}=17.40, \mathrm{P}<0.001$ ) as shown in Figure 3. Higher abundance of insectivorous passerines was recorded in the rocky outcrop and the gallery forest than in the savanna habitat. On the other hand, there was no significant difference in insect abundance recorded between the savanna, gallery forest and the rocky out crop (Kruskal-Wallis test: $\mathrm{df}$ $=2, \chi^{2}=2.13, \mathrm{P}=0.35$ ).

There was a significantly higher diversity of insectivororous passerines in the savanna and the gallery forest than the rocky outcrop (One-way ANOVA: $\mathrm{F}_{2}, \quad 20=0.14, \quad \mathrm{P}<0.001$ ), (Figure 4). A Bornferroni test showed significant difference between gallery and rocky outcrop $(\mathrm{P}=0.04)$ and between savanna and rocky outcrop $(\mathrm{P}=0.03)$. On the other hand, there was no significant difference between insect diversity in the three habitat types (One-way ANOVA: $\mathrm{F}_{2,32}=0.38, \mathrm{P}=0.07$ ), although there were more insect species in the savanna and gallery forest. Diversity of insectivorous passerines and their insect prey collected from the three habitat types, therefore, indicates higher diversity for both birds and insects in the savanna and the gallery forest but lower in the rocky out crop (Figure 4). 


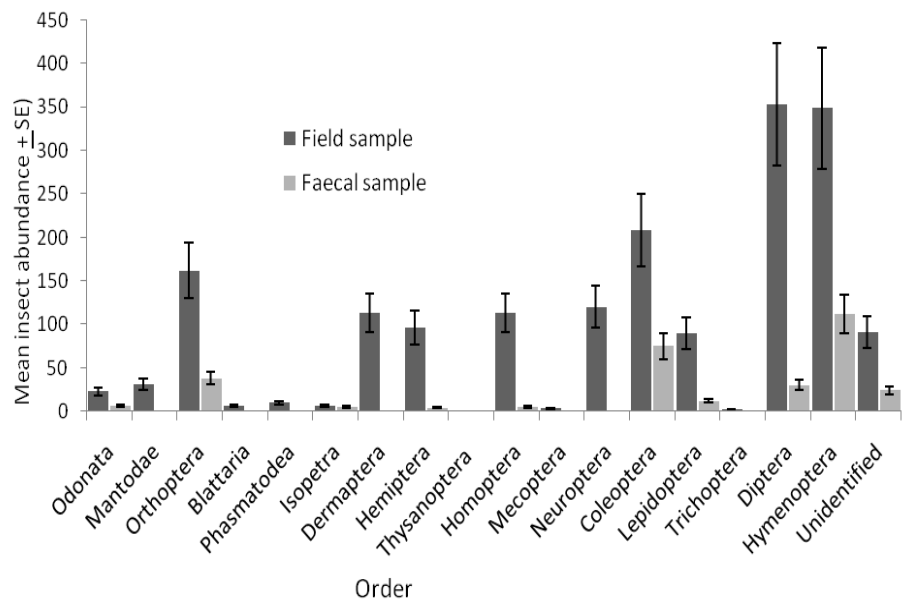

Fig 1. Comparison of Insect Orders Collected from the Field and Faecal Samples

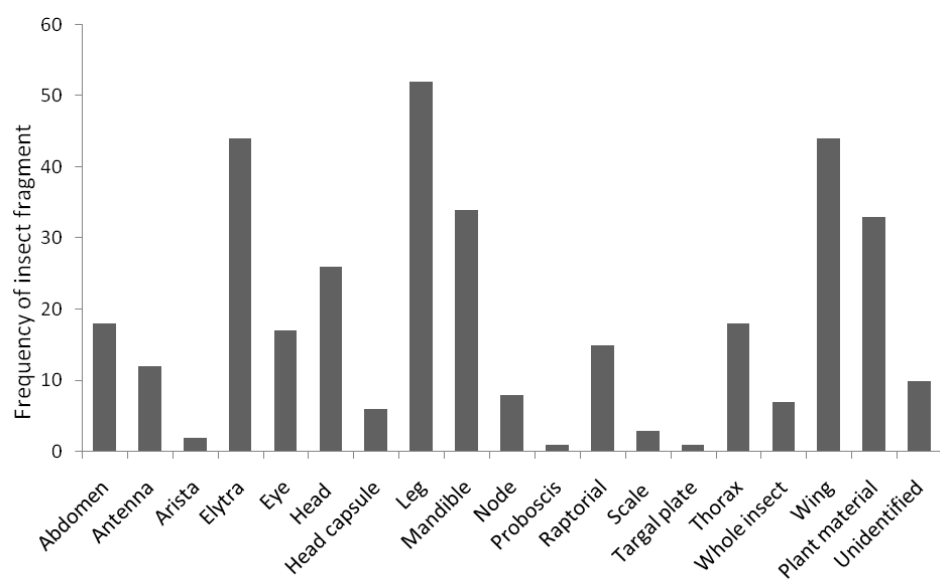

Fig 2. Frequency of Fragments Identified in Faecal Sample of Insectivorous Passerines

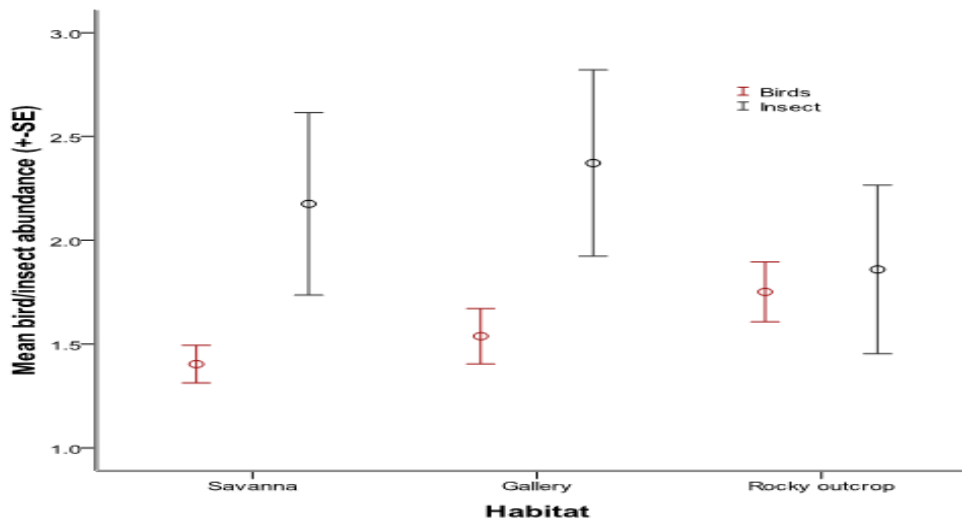

Fig 3. Mean Insectivorous Passerines and their Insect Prey Abundance in the three Habitat types

There was no significant difference in the relationship between insects and insectivorous passerine diversities $(\mathrm{N}=9, \mathrm{r}=-0.278, \mathrm{P}=0.47)$. Pearson correlation between insectivorous passerine diversity and insect diversity showed a positive relationship (Figure 5). There was however, a significant difference in the relationship between insectivorous passerine abundance and insect abundance $(\mathrm{N}=9, \mathrm{r}=0.789, \mathrm{P}=0.018)$. Pearson correlation between insectivorous passerine and insect abundance showed a positive relationship (Figure 6). Understanding the factors that regulate species diversity and abundance in a community is fundamental in contemporary ecology (Hurlbert, 2004). This is why animals are studied in relation to their habitats and other environmental parameters (Hughes et al., 2000). This study underscores the fact that the Jos Wildlife Park is rich in avifauna given that bird species diversity value $\mathrm{H}$ is between 3.62 and 4.12 in this study. Note that for biological communities, species diversity value $\mathrm{H}$ does not exceed 5.0, thus suggesting high bird species diversity in the study area (Ezealor, 2002; Begon et al., 2003). Species abundance and diversity are useful parameters when assessing bird communities; this is because bird species abundance and diversity are known to differ with habitat type (Wiens, 1989; Hughes et al., 2000). The positive correlation observed in the Species Diversity Index $(\mathrm{H})$ of insectivorous passerines and their insect prey from the three habitat types studied are in agreement with previous studies (Yard, et al., 2004; Philpott et al., 2008). The significantly more insectivorous passerines recorded in the savanna and gallery forest habitats compared with the rocky outcrop is perhaps due to higher abundance and diversity of vegetation of these habitat types that eventually translates into higher insect prey abundance (Szaro and Jakle, 1985, Philpott et al., 2008). More vegetation cover with denser tree species was observed in the gallery and savanna habitat types compared with the rocky outcrop where a significant space was covered by rocks and short sparingly distributed trees (Pers. Obs.). Philpott et al., (2008) recorded high bird and ant richness and abundance in habitats with dense trees compared to those with sparingly distributed trees. 


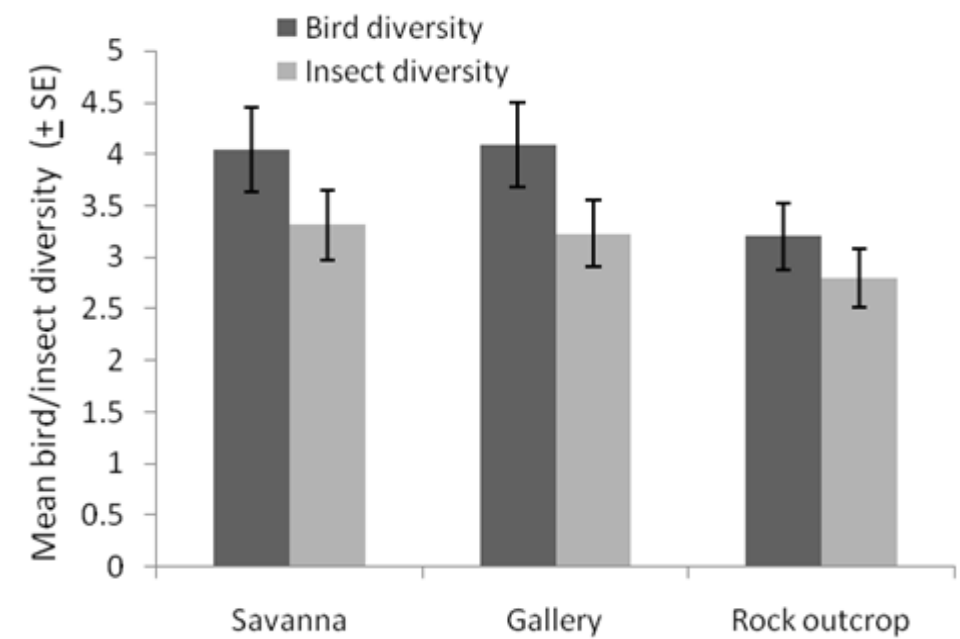

Fig 4. Mean Insectivorous Passerines and their Insect Prey Diversity in the three Habitat types

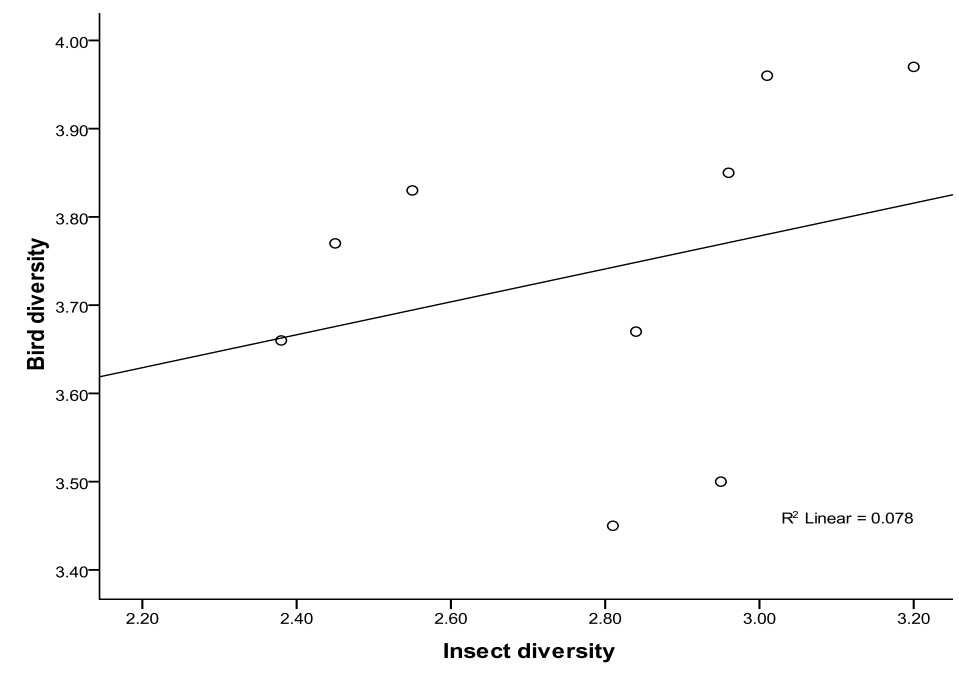

Fig 5. Relationship between Insectivorous Passerines and Insect Species Diversity

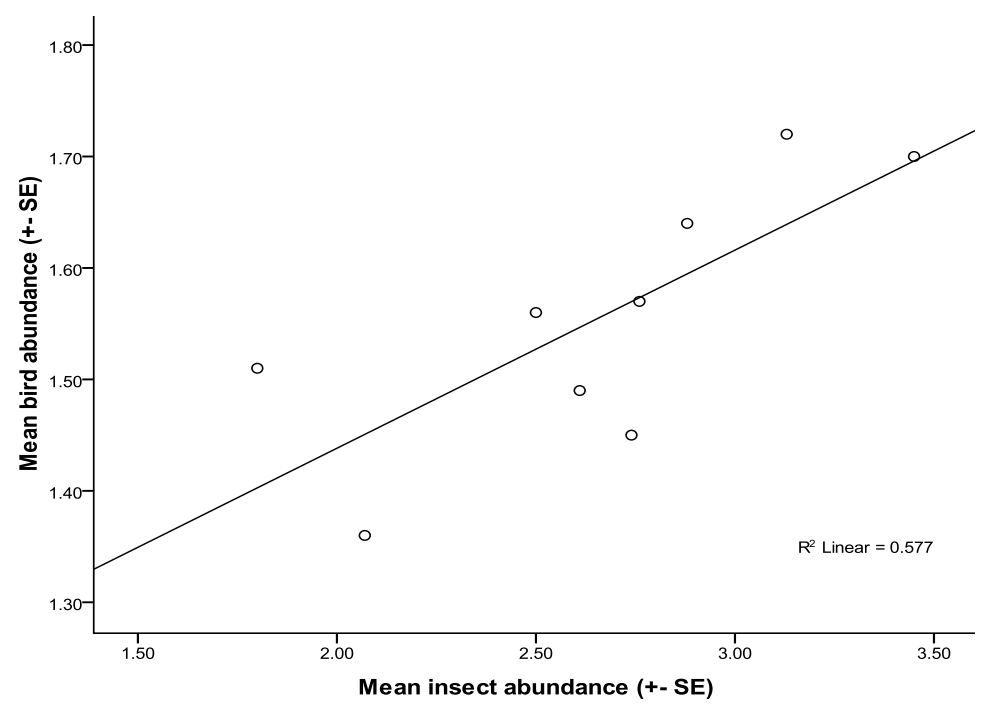

Fig 6. Relationship between Insectivorous Passerines and Insect Species Abundance
This study further demonstrates the positive impact of tree species abundance, richness, diversity and height in the distribution of birds and ants. Studies have shown that animal species do not live in isolation of plants communities (Cody, 1983; Ralph, 2003; Hurlbert, 2004; Wijesinghe and Brooke, 2005; Philpott et al., 2008). These authors found out that tree richness, tree density, canopy cover, tree heights, canopy depth and under-storey heights correlated positively with birds and ants. The higher species abundance and diversity in the gallery and savanna habitats is probably a consequence of the greater complexity of vegetation structure, which creates a greater variety of niches for a wider range of animal species (Wijesinghe and Brooke, 2005). MacArthur and MacArthur, (1961) has earlier pointed out that more complex vegetation support more animal species. Report by Turshak et al., 2010 however showed that there was no significant variation in bird species diversity and abundance between the savanna, gallery forest and the rocky outcrop. This, they attributed to relatively small size and vegetation homogeneity of the study site, Amurum Forest Reserve (300 ha) which may have allowed bird species to move freely from one habitat to the other without having to travel long distances and notwithstanding the variation in macrohabitats. The Jos Wildlife Park $\left(12 \mathrm{~km}^{2}\right)$ is relatively larger in size compared to the Amurum Forest Reserve hence the heterogeneity of the Park and its bird fauna. Another possible explanation for the significant difference in insectivorous passerines abundance and diversity could be linked to the fact that majority of insectivorous passerines are territorial and may not have to travel long distances, there-by resulting in localized populations within habitats. 
According to behavioral ecology and sociobiology, bird species that fed on less than $50 \%$ fruit are most likely to be insectivorous and thus territorial (Fretwell and Lucas, 1969; Burton, 1998). Although there was no statistical difference in insect abundance and diversity, the general trend show that more insects were recorded in the savanna and the gallery forest habitats compared with rocky outcrop. Just as in the case of insectivorous passerines stated earlier, the habitat may also be sufficiently heterogeneous to show significant difference, allowing greater number of birds and insects to become localized within the habitat types.

Conclusion: The paper wish to conclude that insect species abundance and diversity results in increase in the abundance and diversity of insectivorous birds. The commonest insect orders recorded both in faecal droppings of insectivorous passerines and field collection were coleoptera, hymenoptera, diptera and orthoptera. These orders are perhaps the most preferred diet of insectivorous passerines. We also concluded that insectivorous passerines had a direct correlation between habitat resource availability and utilization. There was also a similar trend in the general distribution of insects and bird species across the habitat types.

\section{REFERENCES}

Balmford, A; Long, A (1994). Avian endemism and forest losts. Nature, 372, 623-624.

Begon, M; Harper J.L; Townsend, C. R (2003). Ecology of Individuals, Populations and Communities. ( $4^{\text {th }}$ edition) Blackwell Science Ltd. pp 884-912.

Bibby, C.J; Burgess, N.D; Hill, D.A (2000). Bird Census Techniques. Second Edition. Academic Press London. Pp 65-227.

Borror, D.J; White, R.E (1970). Field guide to the insects of America North of Mexico. Houghton Mifflin Company, Boston.404 pp.

Borrow, N; Demey, R (2008). Birds of Western Africa. Princeton University Press. 511 pp.

Burton, N.H.K (1998). Notes on the diet of nestling White-throated Kingfisher Halcyon smyrnensis in Malaysia. Folktail, 14, 79-80.

Castner, J.L (2000). Photographic Atlas of Entomology and Guide to Insect Identification, Feline Press Inc. 174 pp.
Cody, M.L (1983). Bird diversity and density in South African forest. Oecologia, 59, 201-215.

Ezealor, A. U. (2002). Critical Sites for biodiversity conservation in Nigeria. Nigerian Conservation Foundation (NCF)., Lagos. 110 pp.

Fretwell, D.S; Lucas, H.L. Jr (1969). On territorial behaviour and other factors influencing habitat distribution in birds. Acta Biotheoretica, 19, 16-36.

Hughes, J.B; Daily, G.C; Ehrlich, P.R (2000). Conservation of insect diversity: a habitat approach. Conservation Biology, 14(6), 17881797.

Hurlbert, A.H (2004). Species-energy relationships and habitat complexity in bird communities. Ecology Letters, 7, 714-720.

Karr, J. R; Roth J.J. (1971). Vegetation structure and avian diversity in several New World Areas. American Naturalist, 105, 423-435.

MacArthur, R. H; MacArthur, J.W (1961). On bird species diversity. Ecology, 42, 594-598.

MacArthur, J.W (1964). Environmental factors affecting species diversity. American Naturalist, 98, 387-397.

MacKenzie, D.I; Nichols, J. D (2004). Occupancy as a surrogate for abundance estimation. Ani. Biodiv. Cons., 27(1), 461-467.

Mannok, D.S (2006). Bird species diversity and abundance at the Jos Wildlife Park, Nigeria. M.Sc. thesis, submitted to the University of Jos, Nigeria. 51 pp.

Philpott, S. M; Arendt, W.J; Armbrecht, I; Bichier, P; Diestch, T.V; Gordon, C; Greenberg, R.; Perfecto, I; Reynoso-Santos, R; Soto-Pinto, L; TejedaCruz, C; Williams-Linera, G; Valenzuela, J; Zolotoff, J.M (2008). Biodiversity loss in Latin America coffee landscape: review of the evidence on ants and birds. Cons. Biol. 22(5), 1093-1106.

Ralph, C.J (2003). Habitat association patterns of forest and steppe birds of northern Patagonia, Argentina. The Cooper Ornithological Society, 12, 471-484.

Recher, H. F; Holmes, R. T; Schulz, M.; Shields, J; Kavanagh, R (1985). Foraging patterns of breeding birds in eucalypt forest and woodland of 
southeastern. Australia. Aus. J. Eco. 10, 399419.

Rice, J; Anderson, B.W; Ohmart, R.D (1984). Comparison of the importance of different habitat attributes to avian community organisation. $J$. Wildlife Mgt., 48(3), 895-911.

Robbins, C.S; Sauer J.R.; Greenberg R.S; Droege, S (1989). Population declines in North American birds that migrate to the Neotropics. Proceedings of the National Academy of Science 86, 76587662.

Shattuck, S.O. (2000). Australian ants their biology and identification. CSIRO Publishing. 226 pp.

Skaife, S.H (1979). African Insect Life. Struik Publishers. 354 pp.

Szaro, R. C; Jakle, M (1985). Avian use of a desert riparian island and its adjacent scrub habitat. Condor 87, 511-519.
Turshak, L.G; Manu, S.A; Tiseer, F. (2010). Bird Communities of Amurum Forest Reserve. Report Submitted to APLORI, University of Jos. 41 pp.

Wiens, J.A (ed.) (1989). The Ecology of Birds Communities, Processess and Variations. Cambridge University Press. 316 pp.

Wijesinghe, M.R; Brooke, M.de L (2005). Impact of habitat disturbance on the distribution of endemic species of small mammals and birds in a tropical rain forest in Sri lanka. J. Trop. Eco. 21, 661-668.

Yard, H.K; Van Riper III, C; Brown, B.T; Kearsley, M.J. (2004). Diet of insectivorous birds along the Colorado River in Grand Canyon, Arizona. The Condor, 106, 106-115. 